\title{
Alternative Social Security Systems and Growth
}

\author{
MichaEL KAGANOVICH \\ ITZHAK ZILCHA
}

CESIFO WORKING PAPER NO. 2353

CATEGORY 1: PuBlic FinANCE

JULY 2008
An electronic version of the paper may be downloaded
- from the SSRN website: Www.SSRN.com
- from the RePEc website: Www.RePEc.org
- from the CESifo website: www.CESifo-group.org/wp




\title{
Alternative Social Security Systems and Growth
}

\begin{abstract}
Demographic trends in most developed economies are characterized by rising longevity and decreasing birthrates. These trends endanger the sustainability of the current public pension systems. Therefore social security reform proposals are on the agenda in many countries. This paper demonstrates that the analysis of fiscal sustainability of social security must include an additional dimension of public policy, namely education funding. Indeed, the productivity growth of future workers, which depends on human capital accumulation, may outweigh the impact of the demographic problem. This fact is true under both pay-as-you-go (PAYG) and fully funded (FF) social security system. We consider an OLG economy where government, in addition to running social security, also funds education of future workers by means of taxes collected from the current ones. The education tax rates are chosen, in each period, by a majoritarian rule among the relevant constituents. We demonstrate that while the FF system results in relatively higher rates of physical capital accumulation, then under some conditions, other things equal, the PAYG social security regime leads to the choice of relatively higher respective levels of education tax rates in all generations, and thereby to higher rates of human capital accumulation.
\end{abstract}

JEL Code: I20.

Keywords: social security, funding, growth, human capital.

\author{
Michael Kaganovich \\ Department of Economics \\ Indiana University \\ Wylie Hall \\ Bloomington, IN, 47405 \\ USA \\ mkaganov@indiana.edu
}

\author{
Itzhak Zilcha \\ Tel Aviv University \\ The Eitan Berglas School of Economics \\ P.O.B. 39040 \\ Ramat Aviv, Tel Aviv, 69978 \\ Israel \\ izil@post.tau.ac.il
}

We are grateful to Gerhard Glomm, Volker Meier and conference participants at the 2007 European Meetings of the Econometric Society, PET 2007 and ESPE 2007 for helpful comments and suggestions. We are grateful for the support from the Pinhas Sapir Center for Development, Tel Aviv University. 


\section{Introduction}

In all developed economies longevity continues to rise while birthrates are near or below replacement levels. Both of these demographic trends lead to a decreasing dependency ratio in public pension systems, i.e., the relationship between the number of working adults and the number of recipients of retirement benefits. Social security systems exist in all developed economies and, moreover, it represents the largest public program. The downward trend of the dependency ratio is therefore rightly viewed as the sign of looming crisis of public pension systems, raising doubts about future solvency of existing programs. Hence the social security reform proposals are on the immediate public policy agenda. The public policy debate has stimulated and has relied on empirical and theoretical analyses that attempt to evaluate conditions for sustained solvency of alternative social security arrangements (Diamond (1999), Feldstein (2005))

While this literature focuses on the demographic trend of the dependency ratio for its predictions, a large part of it treats dynamics of future productivity (also a critical component of fiscal sustainability) as exogenously given. Many other papers, e.g., Diamond and Orszag (2005), Hines and Taylor (2005), Sinn (2000), similarly unequivocal about the insolvency, rightly observe that dynamics of future productivity is itself negatively affected by the growth of social security program's obligations, due to the depressing effect on private saving. The effect of introducing social security on savings and welfare has been widely discussed in the literature going back to Feldstein (1974). ${ }^{2}$ Most of this literature, however, tended to overlook the fact that social security system may affect future productivity also through the channel of human capital

\footnotetext{
${ }^{2}$ Karni and Zilcha (1989) provided a general equilibrium analysis of this problem within an OLG framework.
} 
accumulation. A notable exception, in direct response to Feldstein (1974), was the paper by Pogue and Sgontz (1977). They pointed out that a pay-as-you-go (PAYG) social security system creates incentives (both individual and collective) for investment in younger generation's education. Furthermore, they argued that a portion of the consumption increase in the data, interpreted by Feldstein (1974) as an evidence of dissaving triggered by the expected pension transfers, in fact consisted of such human capital investment. Thus, they conjectured that "the introduction of [PAYG] social security has led to a substitution of human for physical capital" and pointed to the post-1938 trends consistent with this claim.

Our intended contribution in this paper is to provide a thorough theoretical analysis of this conjecture in a general equilibrium framework and to demonstrate that the effect of a social security system on human capital accumulation is essential for evaluating its fiscal sustainability. Indeed, as argued above the outlook on solvency depends not only on demographic dependency ratio, but also on productivity of the future work force, hence on investment in human capital. A robust growth of this production factor may serve as a counterweight to the decline of dependency ratio and even a possible reduction, due to aforementioned adverse effects of social security on private saving, in the relative share of physical capital. Note that the growth of future productivity is critical for the solvency of social security not only under PAYG system, where benefits are directly dependent on the stream of payroll taxes paid by future workforce, but also in the case of fully funded social security where investment return on social security's funds depends on future labor productivity. Given the role of human capital in productivity growth, we argue that public funding of education is an important policy dimension affecting fiscal dynamics of a social security system. Therefore this dimension is also essential for a comparative analysis of PAYG and fully funded social security systems, which is the focus of this paper. 
The role of both public and private investment in education in the relationship between social security funding and economic growth was noted and analyzed for the case of PAYG social security by Kaganovich and Zilcha (1999), Glomm and Kaganovich (2003) and Köthenbürger and Poutvaara (2006). ${ }^{3}$ A branch of recent literature which includes Kemnitz (2000), Boldrin and Montes (2005), Poutvaara (2006) and Soares (2006), examines the relationship between public provision of education and PAYG social security as an issue of political economy and intergenerational contract. The present paper is the first to our knowledge to focus on the comparison of PAYG and fully funded social security systems in terms of the incentives they generate for public funding of education, which plays the dominant role in education systems of most developed countries. In particular, we consider the implications of the alternative pension regimes for political determination of public education funding levels, hence for growth in a general equilibrium framework.

In most cases major social security reform proposals discussed in the US and Europe entail a transition from PAYG to a fully funded system. We therefore undertake a comparative analysis of these alternative arrangements in an economy where government, in addition to running social security trust fund, also finances education of future workers by means of taxes collected from the current workers. We use an overlapping generations economy where

\footnotetext{
${ }^{3}$ Some authors have also analyzed interactions between publicly funded social security system and privately funded education. Zhang and Zhang (1998) find that a PAYG social security program can actually speed up economic growth when there are interaction effects with fertility and investment in human capital. Pecchenino and Utendorf (1999) consider a similar setting but assume exogenous fertility; under some conditions they obtain a result opposite to that of Zhang and Zhang (1998): on the margin, social security crowds out education and lowers growth. Docquier and Paddison (2003) compare the implications of PAYG and fully funded social security regimes for growth via individual incentives to invest (privately) in education. Under some conditions they find that the effect of a fully funded system may be positive, while the effect of a PAYG system is negative. Lambrecht et al (2005) qualify that the above conclusion about the negative effect of PAYG systems may be overturned in economies where private bequest motives are inoperative.
} 
individuals differ in the levels of human capital they attain and thereby in the levels of income. In this framework, public funding of education is provided by the government uniformly to all young agents, whereas inequality of attainment arises due to unequal innate abilities and parental inputs. Public funds are budgeted through a dedicated education tax on working adults.

We first assume that the education tax rates across generations are exogenously given and compare economic growth outcomes under alternative social security regimes: PAYG and fully funded. We show that if defined contribution rates are the same the fully funded regime strictly dominates the PAYG regime in terms of human and physical capital creation and thereby in terms of aggregate output at all times from the inception of the pension systems. This means, that when population longevity in the model is high, such that demographic dependency ratio is low, the fully funded social security system is more likely to maintain fiscal sustainability without disrupting economic growth. Furthermore, comparing intragenerational income distributions along the equilibrium paths corresponding to the alternative social security regimes, we find that, under plausible assumptions, PAYG social security system results in higher income inequality relative to the fully funded case.

Next, we abandon the condition of exogenous determination of education taxes and introduce a political mechanism. We assume that the education tax rate is chosen, in each period, by a majoritarian rule among the relevant constituents. We demonstrate that the comparative growth relationship between the alternative social security regimes depends on the initial human capital distribution and the political process. In particular, we show that that under some plausible conditions, the PAYG social security regime can lead to the choice of relatively higher respective levels of education tax rates and thereby to higher rates of human capital accumulation than a fully funded system, controlling for the social security tax rates. Thus, when the political 
dimension of public education funding is taken into account, PAYG social security regime may under some conditions dominate in terms of long-term sustainability prospects given the critical role of human capital as a factor of economic growth. While fully funded social security regime is known to be more favorable (other things equal) than PAYG to private saving and thus to physical capital creation, a notable feature of PAYG system is that it makes pension benefits of future retirees more directly dependent on productivity of future workers.

\section{The Model}

We study an overlapping generations economy populated by heterogeneous family dynasties, indexed by the family name $\omega \in \Omega$. The only sources of heterogeneity are the differences of human capital levels of the members of the initial generation in period $t=0$ and the (random) innate ability. Each generation consists of agents whose adult life has two periods of equal lengths: the young adult age during which each agent inelastically supplies one unit of labor time to work and raises one offspring, and, subject to survival, the old age spent in retirement. Since each young adult produces one offspring, the population remains constant in every generation. Let $\mu$ be the Lebesgue measure on $\Omega$. Without loss of generality we set the measure of individuals born in each generation $\mu(\Omega)=1$. Thus in each time period there is measure 1 of workers and measure 1 of children. At the end of the working period, everyone faces a lottery: dying immediately, or living throughout the entire retirement period. Implicitly, we assume a 'childhood period' in which education is attained and no economic decisions are made. The probability of survival $p$ is identical for all individuals. Since the measure of working population is always 1 , this means that the measure of retired population is always equal to $p$. We label the generation whose young adult age occurs in time period $t$ as "generation $t$ ". An 
individual $\omega$ who belongs to generation $t$ is endowed when entering the adulthood period with the stock of human capital $h_{t}(\omega)$ which also defines his effective labor capacity.

\section{Education Sector}

Human capital $h_{t+1}(\omega)$ of a young individual in generation $t+1$ is produced by using a uniform public education input, but the individual's attainment depends on his parent's level of human capital $h_{t}(\omega)$, which reflects a well established factual such relationship. The public input at date $t$ is given by uniform and universal public expenditure $X_{t}$ on educating each student of generation $\mathrm{t}+1$. We assume the following form of the human capital production function:

$$
h_{t+1}(\omega)=b_{t+1}(\omega)\left(h_{t}(\omega)\right)^{\sigma} X_{t}^{1-\sigma}
$$

where $0<\sigma<1$ while $b_{t+1}(\omega)$ is a random ability parameter which is distributed on $\Omega$, identically at all times with probability measure $\mathrm{P}($.$) independently of h_{t}(\omega)$. Furthermore, realizations of $b_{t+1}(\omega)$ are uniformly bounded above and below by positive numbers.

According to the expression (1) human capital formation is affected by a public component represented by the public spending on education $\mathrm{X}_{t}$ (in both per student and aggregate terms due to our convention that population measure is 1 at all times) as well as a private "home" education component which we assume to be proportionate to human capital level of a student's parent. Thus we can interpret the coefficient $\sigma$ as a measure of efficiency of parental factor in education while $1-\sigma$ characterizes the role of the public component. These parameters may vary across countries reflecting cultural differences in the relative roles of home and public schooling in educating a child. 


\section{Decisions of Individual Agents}

Working adults of generation $\mathrm{t}$ allocate their after-tax wage income $\left(1-\tau_{\mathrm{t}}-\theta_{\mathrm{t}}\right) w_{t} h_{t}(\omega)$ between current consumption $c_{t, t}$ and saving $s_{t}$, thus they face individual budget constraints

$$
\mathrm{c}_{\mathrm{t}, \mathrm{t}}(\omega)+\mathrm{s}_{\mathrm{t}}(\omega)=\left(1-\tau_{\mathrm{t}}-\theta_{\mathrm{t}}\right) w_{t} h_{t}(\omega)
$$

where $w_{t}$ is the current competitive wage rate per unit of the effective labor while $\tau_{\mathrm{t}}$ and $\theta_{\mathrm{t}}$ stand for current (uniform and flat) tax rates earmarked for social security and public education expenditures, respectively, which will be discussed in more detail later.

We assume that public pension benefits $T_{t}$ are uniform across (living) retirees in a given period t. In view of the agents' uncertain survival to retirement, and the lack of bequest motive we assume that they make their private savings in the form of actuarially fair annuities. Individuals are also allowed to borrow against their future assets, in which case the variable $\mathrm{s}_{\mathrm{t}}(\omega)$ has a negative value. The same type of actuarial notes (see Yaari (1965)) can be used to borrow from future (random) income (i.e., buying life insurance). Thus, negative savings are allowed at higher interest rates that reflects the possibility that payback may not occur (in case of death). This corresponds to negative savings which is equivalent to buying life insurance. Let

$R_{t+1}$ denote the gross rate of return on private savings of generation $t$. Then the retirement period budget constraint faced by a surviving member of generation $t$ is given by:

$$
c_{t, t+1}(\omega)=R_{t+1} S_{t}(\omega) / p+T_{t+1}
$$

We assume that fair actuarial notes can be traded in the market hence actuarially fair annuities and life insurance policies are traded via this single financial instrument (see Yaari (1965) for a detailed discussion). 
Each individual in generation $\mathrm{t}$ determines the values of his decision variables $c_{t, t}(\omega), c_{t, t+1}(\omega), s_{t}(\omega)$ so as to maximize the expected utility of his life-time consumption:

$$
\max \operatorname{EU}\left(c_{t, t}(\omega), c_{t, t+1}(\omega)\right)=\ln c_{t, t}(\omega)+p \beta \ln c_{t, t+1}(\omega)
$$

subject to the budget constrains (2)-(3), where the intertemporal discount factor $\beta \in(0,1)$, and the economy's variables $w_{t}, R_{t+1}, T_{t}, \tau_{\mathrm{t}}, \theta_{\mathrm{t}}$ are taken as given.

\section{Government Education and Social Security Budgets}

As stated earlier, public education expenditure $X_{t}$ is funded by a dedicated uniform tax on current wage income, thereby the education budget, assumed balanced at all times, is given by the equation

$$
\mathrm{X}_{\mathrm{t}}=\theta_{t} w_{t} H_{t}
$$

where

$$
H_{t}=\int_{\Omega} h_{t}(\omega) d \mu(\omega)
$$

is the aggregate supply of effective labor, i.e., the human capital, so that $w_{t} H_{t}$ is the aggregate (as well as per capita, since population measure is normalized to one) labor income in period t. We will initially assume that the education tax rates $\theta_{\mathrm{t}}$ are exogenously given, but later, in Section 4 of the paper, we will incorporate it in a political economy model where in each time period $\theta_{\mathrm{t}}$ is determined by a majoritarian rule among the relevant constituents.

In this paper we analyze two alternative funding arrangements for a defined contribution public pension system, both the focal points of the public debates on social security: a fully funded (FF) system and a pay-as-you-go (PAYG) system.

Under the FF social security system, the pension benefits received in period $t+1$ by all surviving retired individuals of generation $\mathrm{t}$ are funded by the proceeds from the payroll tax 
collected at a flat rate $\tau_{\mathrm{F}}$ in period $\mathrm{t}$ from all workers of this same generation. Thereby, the balance of the social security fund, maintained at all times, is given by the equation

$$
T_{t+1}=R_{t+1} \tau_{F} w_{t} H_{t} / p
$$

Thus the social security tax revenue collected from generation $t$ workers is invested in the economy; the gross returns on this investment are then redistributed uniformly in period $t+1$ to surviving retirees.

Under the PAYG system, the pension benefits received by the generation $\mathrm{t}$ retirees are paid for by the payroll tax on contemporary workers, i.e., the young adults of generation $t+1$. We assume that the tax is collected at a flat rate $\tau_{\mathrm{G}}$. Then the PAYG social security benefit received by each surviving member of generation $\mathrm{t}$ (retiree) is given by

$$
T_{t+1}=\gamma w_{t+1} H_{t+1} \quad \text { where } \quad \gamma=\tau_{\mathrm{G}} / \mathrm{p}
$$

Thus unlike the fully funded system where social security fund is a part of national savings, under the PAYG system the payroll tax collected from generation $\mathrm{t}+1$ workers passes through directly to the pension beneficiaries, i.e. they are redistributed among the contemporary retirees in this same time period $\mathrm{t}+1$.

\section{Production Economy and Public Finance}

We assume the standard form of the aggregate production function:

$$
Y_{t}=A K_{t}^{\delta} H_{t}^{1-\delta}
$$

where parameters satisfy $A>0,0<\delta<1, Y_{t}$ is total output, $K_{t}$ is the aggregate stock of physical capital, which is financed by the savings of the previous generation.

In the case of FF public pension system, the aggregate savings include, in addition to the private component, also the savings in the social security trust. Thus one can write 


$$
K_{t+1}=\int_{\Omega} s_{t}(\omega) d \mu(\omega)+\tau_{t} w_{t} H_{t}
$$

When the social security system is PAYG, i.e., the social security payroll tax is spent in the period when it is collected, there are only private savings in the economy, so that the aggregate physical capital in period $\mathrm{t}+1$ is given by

$$
K_{t+1}=\int_{\Omega} s_{t}(\omega) d \mu(\omega)
$$

Based on the above descriptions we can now define the dynamic competitive equilibria in this overlapping generations model.

Definition. Given the initial stock of physical capital $\mathrm{K}_{0}$, the initial distribution of human capital $\mathrm{h}_{0}(\omega)$ and the sequence of education tax rates $\left\{\theta_{t}\right\}_{t=0}^{\infty}$, a dynamic competitive equilibrium (DCE) is a collection of sequences of distributions of individual household decisions $\left\{c_{t, t}(\omega), c_{t, t+1}(\omega), s_{t}(\omega)\right\}_{t=0}^{\infty}$, sequences of distributions of individual levels of human capital $\left\{h_{t+1}(\omega)\right\}_{t=0}^{\infty}$, and of aggregate amounts of physical capital and effective labor $\left\{K_{t}, H_{t}\right\}_{t=0}^{\infty}$, sequences of factor prices $\left\{w_{t}, R_{t}\right\}_{t=0}^{\infty}$, as well as the sequences of government expenditures $\left\{T_{t}, X_{t}\right\}_{t=0}^{\infty}$ such that:

(i) For each $\omega \in \Omega$ and $t=0,1, \ldots$, the collection $c_{t, t}(\omega), c_{t, t+1}(\omega), s_{t}(\omega)$ solves the individual household's problem (2)-(4) where factor prices $w_{t}, R_{t+1}$, social security transfers $T_{t+1}$ and the current tax rates are taken as given;

(ii) Labor markets clear, i.e. given the individual human capital attainments evolve according to (1), the aggregate amount of effective labor $H_{t}$ employed in period $\mathrm{t}$ is determined by formula (6); 
(iii) Physical capital market clears, i.e., the aggregate stock of physical capital $\mathrm{K}_{\mathrm{t}+1}$ employed in period $t+1$ equals to aggregate investment (saving) made in period $t$. Under the fully funded arrangement of the social security system this means that $\mathrm{K}_{\mathrm{t}+1}$ is determined by the relationship (10), whereas under the PAYG system the relationship (11) applies instead.

(iv) Factor markets are competitive, hence according to the economy's production function (9) the factor prices are determined by their marginal products:

$$
\begin{aligned}
& R_{t+1}=\delta Y_{t+1} / K_{t+1}=\delta A K_{t+1}^{\delta-1} H_{t+1}^{1-\delta} \\
& w_{t}=(1-\delta) Y_{t} / H_{t}=(1-\delta) A K_{t}^{\delta} H_{t}^{-\delta}
\end{aligned}
$$

(v) Government expenditures on education $X_{t}$ are determined according to formula (5), where the aggregate wage income as well as the education tax rate are given;

(vi) Social security benefits received by generation $t$ retirees are always defined by the formula (7) or (8) - respectively under the FF or PAYG arrangement.

\section{Growth and inequality under exogenous education funding}

In this section we will first solve the model and derive recursive dynamic relationships that define the DCE under each of the pension systems and an exogenously given sequence of education tax rates $\left\{\theta_{t}\right\}_{t=0}^{\infty}$. We will then compare these DCE outcomes under the fully funded and the PAYG systems in terms of growth and income inequality characteristics. In some instances dictated by the need of reference or clarification we will mark DCE variables and value functions corresponding to the FF system with a superscript ${ }^{\mathrm{F}}$; likewise the superscript ${ }^{\mathrm{G}}$ will be used in such instances in the PAYG case.

Fully Funded Social Security System 
Since pension benefit under the fully funded system is defined by the expression (7), the old-age budget constraint (3) has the form

$$
c_{t, t+1}(\omega)=R_{t+1} S_{t}(\omega) / p+R_{t+1} \tau_{F} w_{t} H_{t} / p
$$

Therefore the first-order necessary (as well as sufficient, due to concavity of the logarithmic utility function) condition of optimum in the household problem (2)-(4) is given by the equation

$$
\frac{p \beta}{s_{t}+\tau_{F} w_{t} H_{t}}=\frac{1}{\left(1-\tau_{F}-\theta_{t}\right) w_{t} h_{t}-s_{t}}
$$

(note that no negativity constraints were imposed on variable $s_{t}$ ). Solving this system we obtain

$$
s_{t}(\omega)=\frac{1}{1+p \beta}\left[p \beta\left(1-\tau_{F}-\theta_{t}\right) w_{t} h_{t}(\omega)-\tau_{F} w_{t} H_{t}\right]
$$

Substitution of this in (2) yields

$$
c_{t, t}(\omega)=\frac{1}{1+p \beta}\left[\left(1-\tau_{F}-\theta_{t}\right) w_{t} h_{t}(\omega)+\tau_{F} w_{t} H_{t}\right]
$$

Similarly, substituting (15) in equation (14) and then applying formula (12) we obtain

$$
\begin{aligned}
c_{t, t+1}(\omega) & =R_{t+1} \frac{\beta}{1+p \beta}\left[\left(1-\tau_{F}-\theta_{t}\right) w_{t} h_{t}(\omega)+\tau_{F} w_{t} H_{t}\right]= \\
& =\delta A H_{t+1}^{1-\delta} K_{t+1}^{\delta-1} \frac{\beta}{1+p \beta}\left[\left(1-\tau_{F}-\theta_{t}\right) w_{t} h_{t}(\omega)+\tau_{F} w_{t} H_{t}\right]
\end{aligned}
$$

We now integrate equation (15) to obtain

$$
\int s_{t}(\omega) d \mu(\omega)=\frac{1}{1+p \beta}\left[p \beta\left(1-\tau_{F}-\theta_{t}\right)-\tau_{F}\right] w_{t} H_{t}
$$

Combining this with the relationship (10) yields

$$
K_{t+1}^{F}=\frac{1}{1+p \beta} p \beta\left(1-\theta_{t}\right) w_{t} H_{t}^{F}
$$


Integrating the expression (1) and using formula (5) and the assumption that child's ability $b_{t+1}(\omega)$ is distributed independently of his parents' human capital $h_{t}(\omega)$ we get the following expression for the dynamics of the aggregate human capital:

$$
H_{t+1}^{F}=B\left[\theta_{t} w_{t} H_{t}^{F}\right]^{1-\sigma} \int\left[h_{t}(\omega)\right]^{\sigma} d \mu(\omega)
$$

where $B=\int b(\omega) d P(\omega)$.

Relationships (18) and (19) show that both $\mathrm{K}_{\mathrm{t}+1}$ and $\mathrm{H}_{\mathrm{t}+1}$ are uniquely determined by the choice of the education tax rate $\theta_{\mathrm{t}}$, as long as the prior period's economic variables are given. These aggregate stocks, in turn determine equilibrium wage and interest rates in period $\mathrm{t}+1$, according to competitive relationships (12)-(13).

The above analysis shows that the dynamic competitive equilibrium has Markov property, i.e. current DCE variables can be determined recursively based on their values in the previous period as well as the education tax rate given for that period. Indeed, we have shown that given the DCE fundamentals at time t, namely the stocks of physical capital $K_{t}$ and human capital $H_{t}$, the distribution of individual levels of human capital $\left\{h_{t}(\omega)\right\}$, and the education tax rate $\theta_{t}$, one can uniquely determine the next period's fundamentals $K_{t+1}, H_{t+1}$, the distribution of individual household consumption and saving decisions characterized by (15) and (using formulae (1) and (5)) the distribution of human capital $\left\{h_{t+1}(\omega)\right\}_{\mathrm{T} 0 \Sigma}$. Note that DCE wage and interest rates are also uniquely determined by the economy's contemporary fundamentals according to (12)-(13).

The recursive determination of DCE also implies that welfare of households in generation $\mathrm{t}$ attained in DCE, i.e. the maximum value function in (4), are uniquely determined by the education tax rate $\theta_{t}$ levied from them. This justifies their notation as $V_{t}\left(\omega, \theta_{t}\right)$ for $\omega \in \Omega$. 
Substituting the optimal solution given by (16) and (17) into the utility function (4) and then applying relationships (18) and (19) we obtain:

$$
V_{t}^{F}\left(\omega, \theta_{t}\right)=(1+p \beta) \ln \left[\left(1-\tau_{F}-\theta_{t}\right) h_{t}(\omega)+\tau_{F} H_{t}\right]-p \beta(1-\delta) \ln \left(1-\theta_{t}\right)+p \beta(1-\delta)(1-\sigma) \ln \theta_{t}+D_{t}
$$

where $D_{t}$ is an expression that does not depend on individual decision variables or $\theta_{t}$. We transform the argument of the first logarithmic function in the above expression:

$$
\left(1-\tau_{F}-\theta_{t}\right) h_{t}(\omega)+\tau_{F} H_{t}=h_{t}(\omega)\left[1-\theta_{t}-\tau_{F}\left(1-H_{t} / h_{t}(\omega)\right)\right]
$$

and denote

$$
g_{t}(\omega)=\tau_{F}\left(1-H_{t} / h_{t}(\omega)\right)
$$

-- a variable which corresponds to deviation of individual human capital and income from respective current averages. Substituting this expression into the above welfare function we can rewrite as

$$
V_{t}^{F}\left(\omega, \theta_{t}\right)=(1+p \beta) \ln \left[1-\theta_{t}-g_{t}(\omega)\right]-p \beta(1-\delta) \ln \left(1-\theta_{t}\right)+p \beta(1-\delta)(1-\sigma) \ln \theta_{t}+D_{t}^{1}
$$

where $D_{t}^{1}$ is again an expression that does not depend on individual decision variables or $\theta_{t}$.

\section{Pay-as-you-go Social Security System}

Derivations here are similar to those obtained for the case of fully funded system, with differences due to the fact that relationships (8) and (11) need to be used in place of (7) and (10), respectively. According to (8), the old-age budget constraint (3) under the PAYG system has the form

$$
c_{t, t+1}(\omega)=R_{t+1} S_{t}(\omega) / p+\gamma w_{t+l} H_{t+1}
$$

Therefore the first-order necessary and sufficient condition of optimum in the household problem (2)-(4) is given by the equation 


$$
\frac{p \beta}{s_{t}+p \gamma w_{t+1} H_{t+1} / R_{t+1}}=\frac{1}{\left(1-p \gamma-\theta_{t}\right) w_{t} h_{t}-s_{t}}
$$

Solving this system and using relationships (12) and (13) we obtain

$$
(1+p \beta) s_{t}(\omega)+p \gamma(1-\delta) \delta^{-1} K_{t+1}=p \beta\left(1-p \gamma-\theta_{t}\right) w_{t} h_{t}(\omega)
$$

so that

$$
s_{t}(\omega)=\frac{1}{1+p \beta}\left[p \beta\left(1-p \gamma-\theta_{t}\right) w_{t} h_{t}(\omega)-p \gamma(1-\delta) \delta^{-1} K_{t+1}\right]
$$

Substituting this in relationship (2) we obtain

$$
c_{t, t}(\omega)=\frac{1}{1+p \beta}\left[\left(1-p \gamma-\theta_{t}\right) w_{t} h_{t}(\omega)+p \gamma(1-\delta) \delta^{-1} K_{t+1}\right]
$$

Similarly, substituting (24) in (22) and then using relationships (12)-(13) results in

$$
c_{t, t+1}(\omega)=\frac{R_{t+1}}{p}\left[\frac{p \beta}{1+p \beta}\left(1-p \gamma-\theta_{t}\right) w_{t} h_{t}(\omega)-\frac{1}{1+p \beta} p \gamma(1-\delta) \delta^{-1} K_{t+1}\right]+\frac{R_{t+1}}{p} \frac{p \gamma w_{t+1} H_{t+1}}{R_{t+1}}
$$

$$
=\frac{R_{t+1}}{p} \frac{p \beta}{1+p \beta}\left[\left(1-p \gamma-\theta_{t}\right) w_{t} h_{t}(\omega)+p \gamma(1-\delta) \delta^{-1} K_{t+1}\right]
$$

Further, according to (6) and (11) the integration of (23) yields

$$
\left[1+p \beta+p \gamma(1-\delta) \delta^{-1}\right] K_{t+1}=p \beta\left(1-p \gamma-\theta_{t}\right) w_{t} H_{t}
$$

which leads to

$$
K_{t+1}^{G}=\frac{p \beta\left(1-p \gamma-\theta_{t}\right) w_{t} H_{t}}{1+p \beta+p \gamma(1-\delta) \delta^{-1}}
$$

Note also that relationship (19) applies here without change, so we rewrite for future reference:

$$
H_{t+1}^{G}=B\left[\theta_{t} w_{t} H_{t}^{G}\right]^{1-\sigma} \int\left[h_{t}(\omega)\right]^{\sigma} d \mu(\omega)
$$


The above analysis confirms (see a similar explanation in the case of fully funded system) a recursive determination of the dynamic competitive equilibrium: given the stocks $K_{t}$ and $H_{t}$, the distribution $h_{t}(\omega)$, as well as the education tax rate $\theta_{t}$, the above relationships (27), (28) and (1) along with (5) will uniquely determine the next period's fundamentals $K_{t+1}, H_{t+1}$, distribution of human capital $h_{t+1}(\omega)$.

To obtain the maximum welfare value function $V_{t}\left(\omega, \theta_{t}\right)$ of a generation $\mathrm{t}$ agent $\omega$ we first substitute the expressions for the young- and old-age consumption given by formulae (25) and (26), respectively, into the utility function (4), then apply relationships (12), (13) :

$$
V_{t}^{G}\left(\omega, \theta_{t}\right)=(1+p \beta) \ln \left[\left(1-p \gamma-\theta_{t}\right) w_{t} h_{t}(\omega)+p \gamma(1-\delta) \delta^{-1} K_{t+1}\right]+p \beta(1-\delta)\left[\ln \left(H_{t+1}\right)-\ln \left(K_{t+1}\right)\right]+G_{t}
$$

where $G_{t}$ is an expression that does not depend on decision variables or $\theta_{t}$. Now we use expressions (27) and (28) to further derive:

$$
\begin{aligned}
V_{t}^{G}\left(\omega, \theta_{t}\right) & =(1+p \beta) \ln \left(1-p \gamma-\theta_{t}\right)+p \beta(1-\delta)(1-\sigma) \ln \theta_{t}-p \beta(1-\delta) \ln \left(1-p \gamma-\theta_{t}\right)+G_{1} \\
& =(1+p \beta \delta) \ln \left(1-p \gamma-\theta_{t}\right)+p \beta(1-\delta)(1-\sigma) \ln \theta_{t}+G_{t}^{1}
\end{aligned}
$$

where $G_{t}^{1}$ is an expression that does not depend on decision variables or $\theta_{t}$. This is clearly a strictly concave function of parameter $\theta_{t}$.

Based on the derived DCE relationships we shall now compare the effects of the two social security regimes on growth and distribution within the confines of the experiment defined by the following two conditions:

Condition 1. A social security system (FF or PAYG) is instituted (announced) in the economy at $\mathrm{t}=0$ in the sense that generation 0 is its first beneficiary under either regime, i.e. first social security payments are issued at $\mathrm{t}=1$. (Note that in the case of PAYG system this means that 
generation 0 is in the exceptional position of receiving the benefit without having to pay the social security tax.) Furthermore, for the purposes of the comparative analysis we assume that the social security tax rates applied under the FF and PAYG systems are identical, i.e., $\tau_{F}=\tau_{G}=p \gamma$.

Condition 2. The same sequence of education tax rates $\left\{\theta_{t}\right\}_{t=0}^{\infty}$ is exogenously given for both social security regimes.

The following Proposition, proved in the Appendix, compares the implications of the two social security regimes for economic growth under the provisions of Conditions 1 and 2.

Proposition 1. Assume that each of the alternative FF and PAYG social security regimes satisfies Conditions 1 and 2. Then, $K_{t}^{F}>K_{t}^{G}$ and $Y_{t}^{F}>Y_{t}^{G}$ for $t=1,2, \ldots$, while $h_{t}^{F}(\omega)>$ $h_{t}^{G}(\omega)$ for all $\omega \in \Omega$ and $t=2,3, \ldots .^{4}$ Thus the fully funded regime strictly dominates the PAYG regime in terms of both human and physical capital creation and thereby in terms of aggregate output at all times from the inception of the systems.

We shall now consider, within the provisions of the comparative experiment defined by the above Conditions 1 and 2, the dynamics of intragenerational income inequality resulting under these two regimes of social security programs. The comparison of any two income distributions with respect to inequality will be through the partial ordering of the second degree stochastic dominance (see, Atkinson (1970)):

\footnotetext{
${ }^{4}$ Note that according to the relationships (1) and (5) $h_{1}^{F}(\omega) \equiv h_{1}^{G}(\omega)$ for the initial young generation.
} 
Definition: Income distribution $Y(\omega)$ is more unequal than income distribution $Y^{*}(\omega)$ if $\frac{Y^{*}(\omega)}{E\left[Y^{*}(\omega)\right]}$ stochastically dominates $\frac{Y(\omega)}{E[Y(\omega)]}$ in second-degree, i.e. the Lorenz curve of $Y^{*}(\omega)$ lies strictly above that of $Y(\omega)$.

Starting from a given initial human capital distribution $h_{0}(\omega)$ and $K_{0}, H_{0}$, let us define the present actuarial values of lifetime income for each generation $t=1,2, \ldots$ under the alternative social security regimes provided that social security tax rates are the same: $\tau_{t}^{F}=\tau_{t}^{G} \equiv p \gamma$ for all $\mathrm{t}$, as required by Condition 1 .

For the exogenously given sequence of education tax rates $\left\{\theta_{t}\right\}_{t=0}^{\infty}$ the present actuarial value of lifetime income of generation $t$ under the fully funded regime is:

$$
I_{t}^{F}(\omega)=\left(1-p \gamma-\theta_{t}\right) w_{t} h_{t}(\omega)+p\left[\frac{p \gamma w_{t} H_{t}^{F}}{p}\right]
$$

This can be rewritten as:

$$
I_{t}^{F}(\omega)=B_{t}\left\{\frac{h_{t}^{F}(\omega)}{H_{t}^{F}}+\frac{p \gamma}{1-p \gamma-\theta_{t}}\right\}
$$

where $B_{t}$ is positive and independent of $\omega$,

Now we derive a similar expression for the present actuarial value of lifetime income under PAYG social security:

$$
I_{t}^{G}(\omega)=\left(1-p \gamma-\theta_{t}\right) w_{t} h_{t}(\omega)+\frac{p \gamma w_{t+1} H_{t+1}^{G}}{R_{t+1}}=M_{t}\left\{\frac{h_{t}^{G}(\omega)}{H_{t}^{G}}+\frac{p \gamma}{1-p \gamma-\theta_{t}} \frac{w_{t+1} H_{t+1}^{G}}{w_{t} H_{t}^{G}} \frac{1}{R_{t+1}}\right\}
$$

where $M_{t}$ is positive and independent of $\omega$.

According to the definition of the production function in (9) we obtain that, 


$$
\frac{1}{R_{t+1}} \frac{w_{t+1} H_{t+1}^{G}}{w_{t} H_{t}^{G}}=\frac{1}{\delta Y_{t+1}^{G} / K_{t+1}^{G}}\left[\frac{(1-\delta) Y_{t+1}^{G}}{(1-\delta) Y_{t}^{G}}\right]=\frac{K_{t+1}^{G}}{\delta Y_{t}^{G}}
$$

Using equation (27) we can write:

$$
\frac{K_{t+1}^{G}}{\delta Y_{t}^{G}}=\frac{1}{\delta Y_{t+1}^{G}} \frac{p \beta\left(1-p \gamma-\theta_{t}\right) w_{t} H_{t}^{G}}{1+p \beta+p \gamma(1-\delta) \delta^{-1}}=\frac{p \beta\left(1-p \gamma-\theta_{t}\right)}{(1+p \beta)(1-\delta)^{-1} \delta+p \gamma}
$$

Combining this with equation (32) we rewrite equation (31):

$$
I_{t}^{G}=M_{t}\left\{\frac{h_{t}^{G}(\omega)}{H_{t}^{G}}+\frac{p^{2} \gamma \beta}{p \gamma+(1+p \beta) \delta(1-\delta)^{-1}}\right\}
$$

To proceed with our comparison exercise we note that $\frac{h_{t}^{G}(\omega)}{H_{t}^{G}}=\frac{h_{t+1}^{F}(\omega)}{H_{t}^{F}}$ for all $\omega$ and all $t$, i.e. the choice of a social security system, other things being equal, while differently affecting income levels of individuals will have identical effects on their relative positions in the distribution of incomes. This follows directly from the human capital accumulation process given by (1) and the fact that the given initial human capital distribution $h_{0}(\omega)$ is the same for both dynamic equilibria (see the proof of Proposition 1 for more details). Using the expressions in (30) and (33), we can state

Fact: $I_{t}^{G}(\omega)$ is more unequal than $I_{t}^{F}(\omega)$ if and only if the following inequality is valid:

$$
\frac{1}{1-p \gamma-\theta_{t}}>\frac{p \beta}{p \gamma+(1+p \beta) \delta(1-\delta)^{-1}}
$$

This fact follows from the following known result (see, e.g., Karni and Zilcha (1994)):

Lemma 1: Consider a positive random variable $I(\omega)$ with finite mean $\bar{I}=E[I(\omega)]$. For any two non-negative constants $a, b$ that satisfy $a>b$, we have: distribution $\frac{I(\omega)+a}{\bar{I}+a}$ dominates 
in terms of second degree stochastic dominance, distribution $\frac{I(\omega)+b}{\bar{I}+b}$.

We rewrite inequality (34) as equivalent to $p \beta<p \gamma+(1+p \beta) \delta(1-\delta)^{-1}$ or

$$
p \beta\left(1-p \gamma-\theta_{t}\right)<p \gamma+(1+p \beta) \delta(1-\delta)^{-1}
$$

Note that condition (35) certainly holds under parameter values typical of developed economies: for example, it is by far warranted if the capital income share $\delta$ is around 0.3 while the social security tax rate $p \gamma$ is at least 0.07 .

The above argument proves the following result:

Proposition 2: Assume that each of the alternative FF and PAYG social security regimes satisfies Conditions 1 and 2. Then the inequality ranking of equilibrium intragenerational income distributions under the alternative regimes is determined by whether the parametric inequality (35) or its opposite is satisfied. In particular, if (35) is satisfied in period $t$, then the income distribution attained in a dynamic equilibrium in period $t$ under the pay-as-you-go regime is more unequal than the one distribution under the fully-funded regime.

Thus we have obtained strict ranking of equilibrium income distributions resulting under the two social security regimes: When the model's parameters satisfy condition (35) imposed on the model's parameters the fully funded system results in a more equal distribution of income. However, if the inequality in condition (35) is reversed then the result reverses as well: Under PAYG regime, income distribution is more equal than in the fully funded case. Note that if a stricter condition

$$
p \beta(1-p \gamma)<p \gamma+(1+p \beta) \delta(1-\delta)^{-1}
$$


holds then (35) is met at all times, hence according to the Proposition the income distribution under the PAYG regime is at all times more unequal than the income distribution under the fullyfunded regime for respective dynamic equilibria.

\section{Comparative Analysis of Dynamic Political Equilibrium}

We now define the political economy mechanism that determines the sequence of education tax rates $\theta_{\mathrm{t}}$. Recall that the dynamic competitive equilibrium (DCE) (see its definition in Section 2) corresponds to a sequence of education tax rates $\left\{\theta_{t}\right\}_{t=0}^{\infty}$ assumed to be exogenously given. As demonstrated in Section 3, the DCE has Markov property, i.e., it can be defined recursively: given the DCE variables up to time $t$, the choice of tax rate $\theta_{t}$ uniquely determines the relevant batch of individual, aggregate, and policy variables of the DCE for the current period. In particular, the choice of $\theta_{\mathrm{t}}$ determines the solution $\left\{c_{t, t}(\omega), c_{t, t+1}(\omega), s_{t}(\omega)\right\}$ of each household's problem (2)-(4) in DCE as a function of $\theta_{t}$, and thereby the levels of welfare (4) attained by the households. Thus we have denoted these maximum value levels for each household $\omega \in \Omega$ explicitly as functions of $\theta_{\mathrm{t}}$, namely $V_{t}\left(\omega, \theta_{t}\right)$. It is important to observe that a choice of tax level $\theta_{\mathrm{t}}$ affects welfare of generation $\mathrm{t}$ individuals in two ways. The first effect is on the expenditure side: the tax obviously reduces their disposable income as seen from the budget equation (2). Secondly, it affects both their private retirement savings and public pension benefits expressed in formula (3). Indeed, it contributes to the next generation's aggregate human capital $H_{t+1}$ and thereby enhances return on the generation $\mathrm{t}$ retiree's private investment; furthermore, formulae (7) and (8) show that under each of the alternative social security systems, a higher level of $H_{t+1}$ also enhances public pensions received by generation $\mathrm{t}$ agents. Also note 
that the welfare of generation $\mathrm{t}-1$ retirees who are alive in period $\mathrm{t}$ is unaffected by the choice of tax rate $\theta_{\mathrm{t}}$. Therefore we assume that only generation $\mathrm{t}$ individuals will be involved in the political process of determining the choice of $\theta_{t}$.

Definition: Given the initial stock of physical capital $K_{0}$ and the initial distribution of human capital $\mathrm{h}_{0}(\omega)$ for $\omega \in \Omega$, a dynamic political equilibrium (DPE) is a sequence of education tax rates $\left\{\theta_{t}\right\}_{t=0}^{\infty}$ along with the corresponding dynamic competitive equilibrium (DCE) such that in any time period $\mathrm{t}$ the level of education tax rate $\theta_{\mathrm{t}}$ is the most preferred by a majority of generation $\mathrm{t}$ individuals. In other words, any change in the value of $\theta_{\mathrm{t}}$ accompanied by the corresponding change in DCE would reduce welfare levels for a majority of generation $t$ individuals.

We will now compare the dynamic political equilibria resulting under the PAYG and fully funded social security regimes.

Pay-as-you-go Social Security System

The first order necessary and sufficient condition of maximum of the strictly concave welfare function $V_{t}^{G}\left(\omega, \theta_{t}\right)$ defined by the expression (29) is:

$$
\frac{\partial}{\partial \theta} V_{t}^{G}\left(\omega, \theta_{t}\right) \equiv-\frac{1+p \beta \delta}{1-p \gamma-\theta}+\frac{p \beta(1-\delta)(1-\sigma)}{\theta}=0
$$

Solving this equation we obtain the value of the optimal tax rate:

$$
\theta_{t}^{G} \equiv \theta^{G}=\frac{p \beta(1-p \gamma)(1-\delta)(1-\sigma)}{1+p \beta(1-\sigma+\delta \sigma)}
$$


Thus under the PAYG regime the welfare maximizing education tax rate is the same for all households $\omega \in \Omega$, moreover it is constant over time. Thus the DPE sequence of education tax rates under PAYG social security is given by the stationary optimal rate $\theta^{G}$.

Note that according to expression (38) the optimal education tax rate $\theta^{G}$ is increasing with longevity, namely, that

$$
\frac{\partial \theta^{G}}{\partial p}>0
$$

This is due to two effects of increasing longevity: it increases the weight of utility of the old-age consumption in individuals' welfare function; on the other hand the actuarial value of lifetime income becomes more dependent on the social security tax revenues from future workers. We also observe that $\frac{\partial \theta^{G}}{\partial \sigma}<0$, i.e. the optimal level of education tax is lower the higher is the relative effectiveness of the home component in educating a child.

\section{Fully Funded Social Security System}

Optimal values of education tax rates are defined here by maximizing welfare function $V_{t}^{F}\left(\omega, \theta_{t}\right)$ given by expression (21). Denote by $\theta_{t}^{F}(\omega)$ the optimal choice of education tax by

agent $\omega$ at date t. It is clear that, unlike the PAYG case, individually optimal tax rates $\theta_{t}^{F}(\omega)$ differ across households and time.

The first order necessary condition of maximum of function $V_{t}^{F}\left(\omega, \theta_{t}\right)$ is:

$$
\frac{\partial}{\partial \theta} V_{t}^{F}\left(\omega, \theta_{t}\right)=-\frac{1+p \beta}{1-g_{t}(\omega)-\theta}+\frac{p \beta(1-\delta)}{1-\theta}+\frac{p \beta(1-\delta)(1-\sigma)}{\theta}=0
$$


where function $g_{t}(\omega)$ is as defined in (20). Note that according to relationship (20) the value of $g_{t}(\omega)$ is positive if and only if $h_{t}(\omega)>H_{t}$, i.e., for households with above average income.

By directly comparing expressions (40) and (37) we see that if $g_{t}(\omega) \leq 0$, which means that income of household $\omega$ is at or below the average, then $\frac{\partial}{\partial \theta} V_{t}^{F}(\omega, \theta)>\frac{\partial}{\partial \theta} V_{t}^{G}(\omega, \theta)$ for any given value of $\theta \in(0,1)$. Since $\frac{\partial}{\partial \theta} V_{t}^{G}\left(\omega, \theta^{G}\right)=0$ this means that $\frac{\partial}{\partial \theta} V_{t}^{F}\left(\omega, \theta^{G}\right)>0$ for all households with income at or below average. Thus all such households would always prefer that the education tax rate was set above $\theta^{G}$, i.e., the DPE value corresponding to the PAYG regime.

Consider now preferences of the households with above average income, i.e. such that $g_{t}(\omega)>0$. It is easy to see that the welfare function $V_{t}^{F}\left(\omega, \theta_{t}\right)$ is strictly concave when $g_{t}(\omega) \geq 0$, therefore the most preferred education tax rates $\theta_{t}^{F}(\omega)$ for such households are uniquely defined. By differentiating the expression (40) with respect to household-specific value $g_{t}(\omega)$ one can see that $\frac{\partial^{2}}{\partial \theta \partial g} V_{t}^{F}\left(\omega, \theta_{t}\right)<0$ which means that higher income households would always prefer to reduce the education tax rate chosen by the relatively lower income households. We can summarize this analysis as the following

Lemma 2: Under fully funded social security, the most preferred education tax rates $\theta_{t}^{F}(\omega)$ of households with above average incomes are uniquely defined and satisfy equation (40). Furthermore, the most preferred rate $\theta_{t}^{F}(\omega)$ is a decreasing function of household income.

Assume now that the social security tax rate under the fully funded system is identical to that of the PAYG regime, i.e., $\tau_{F}=p \gamma$. Then the function $g_{t}(\omega)$ is bounded above by $p \gamma$ but 
approaches it as household income grows relative to the mean. By continued comparison of relationships (37) and (40) one can see that when $g_{t}(\omega)$ is close enough to $p \gamma$, then $\frac{\partial}{\partial \theta} V_{t}^{F}(\omega, \theta)<\frac{\partial}{\partial \theta} V_{t}^{G}(\omega, \theta)$ holds for all $\theta$, so the households with relatively high values of $g_{t}(\omega)$ prefer education tax rate lower than $\theta^{G}$. Given the continuous negative relationship between the value of $g_{t}(\omega)$ (when it is positive) and a household's most preferred level of education tax rate, as stated in Lemma 2, there is a cut-off value such that for all households with $g_{t}(\omega)$ above that level, i.e., all households with income above the corresponding cut-off level, prefer that the education tax rate will be below $\theta^{G}$. This result can be formulated as follows.

Lemma 3: Assume that the social security tax rates applied under the FF and PAYG systems are identical, i.e., $\tau_{F}=\tau_{G}=p \gamma$. Then there is a number (the cut-off level of relative income) $h^{F}>1$ such that for all households with higher relative income, i.e. $\frac{h_{t}(\omega)}{H_{t}}>h^{F}$ the most preferred education tax rate $\theta_{t}^{F}(\omega)$ under the FF social security regime for generation $t$, is below the value $\theta^{G}$ they would choose under the PAYG system.

Lemma 3 implies that if median of the relative income $\frac{h_{t}(\omega)}{H_{t}}$ of the voters exceeds the value $h^{F}$, then DPE education tax rate chosen under the fully funded regime is lower than $\theta^{G}$. Note that according to the evolution of human capital distribution defined by expression (1) if the above condition is valid at $\mathrm{t}=0$, it will be also true for $\mathrm{t}=1,2, \ldots$. Since $h^{F}>1$, this condition means that the median income of the voters is sufficiently higher than the mean income of the entire working population. It is a well known fact that the wealthier segments of the population typically have higher voting rate: see, for example, the findings in Nelson (1999) and Mahler 
(2006). In particular, according to Table 3 in Mahler (2006), which summarizes data compiled in the Comparative Study of Electoral Systems (2005), the median voter in 1996 US general elections was close to the 40 -th percentile of income distribution. Also note that in a more complex reality of political process, wealthier individuals can have additional channels, other than direct voting, to exert a disproportionate influence on policy decisions. In sum, it is reasonable to make an assumption that the outcome of a political process represents a preference of an individual with higher than average income, even if the overall income distribution is right skewed.

Given the initial human capital distribution $h_{0}(\omega)$ we thus impose:

Condition 3. The median relative income $\frac{h_{0}(\omega)}{H_{0}}$ of the voters at $\mathrm{t}=0$ exceeds the value $h^{F}$ defined in Lemma 3.

We can then summarize the results of the above analysis:

Theorem: Assume that under both FF and PAYG social security regimes Conditions 1 and 3 hold. Then, DPE education tax rates $\theta_{t}^{F}$ chosen at $t=0,1, .$. under the fully funded social security regime are below the DPE value $\theta^{G}$ obtained under the PAYG regime.

The intuition for the Theorem's result can be obtained by comparing the effects of the choice of an education tax rate $\theta_{t}$ on individual households under the FF and PAYG regimes (see, in particular, expressions (17) and (21) under FF vs. (26) and (29) under PAYG). Such examination shows that under the PAYG system the choice of $\theta_{t}$ affects all households proportionately, which is due to the fact that redistributive pension formula is tied under PAYG 
to wages of the next generation. As a result, the optimal value of education $\operatorname{tax} \theta^{G}$ given by formula (38) is the preferred uniform tax chosen by all households. By contrast, the effect of the choice of $\theta_{t}$ under the FF regime is not proportionate: since this system redistributes wage incomes among the pension recipients, the cost of education tax relative to one's contribution to the pension system is greater for higher income workers. As a result the most preferred education rate $\theta_{t}^{F}(\omega)$ decreases in household's income, as stated in Lemma 2.

Thus, if Condition 2 of Section 3, according to which education tax rates are exogenously determined, is abandoned and instead a political mechanism is considered such that the education tax rate in each period is determined by majority of the relevant constituents, then the domination of the FF regime over PAYG in terms of economic growth, as established by Proposition 1, is called into question. Indeed, while according to expressions (18) and (27) the FF regime is more conducive, ceteris paribus, of physical capital accumulation than PAYG, the opposite holds for the accumulation of human capital under the provisions of the Theorem since they imply that DPE education tax rates are higher under the PAYG regime. Therefore the possibility that the latter advantage of PAYG system can translate into higher rates of overall economic growth depends on whether it outweighs the comparative advantage of the FF regime on the physical capital side.

Due to the limitations of the present model, such a clear-cut growth dominance result cannot be obtained under reasonable assumptions. One of such limitations is that under the model's simple demographic and tax structure, all the retirees remain neutral in the political process determining the current education tax rate since they neither pay it nor stand to benefit from the future productivity gains the tax will finance. A more realistic model of education finance in most developed countries should include the retirees in the tax base (as, for example, 
in Gradstein and Kaganovich, 2004). This would (and does in reality) create a large voting block opposed to raising education taxes and would therefore shift the median voter further into the right tail of the income distribution in the working population (recall that due to mortality population of retirees is smaller than that of workers). It appears plausible that this will imply a stronger dominance of the education tax rate chosen in political equilibrium under the PAYG system compared to the one chosen when pensions are fully funded, sufficiently so to also yield dominance in the overall growth rates. Such a model, however, adds an extra layer of technical complexity and we leave it outside the scope of the present paper.

Turning to the comparisons of income distributions resulting under PAYG and FF regimes, we find that the fact of Proposition 2, along with its proof, completely carries over to the comparison of dynamic political equilibria. Given the tax rates $\theta_{t}^{F}(\omega)$ and the corresponding $\operatorname{tax} \theta_{t}^{F}$ that is chosen in by majority rule in DPE under the FF regime, condition (35) is replaced by the similar one:

$$
p \beta\left(1-p \gamma-\theta_{t}^{F}\right)<p \gamma+(1+p \beta) \delta(1-\delta)^{-1}
$$

Corollary: Let the provisions of the above Theorem be satisfied. Then the inequality ranking of DPE intragenerational income distributions under the alternative regimes is determined by whether inequality (41) or its opposite is satisfied. In particular:

(i) If (41) is satisfied in period $t$, then the income distribution attained in a dynamic equilibrium in period $t$ under the pay-as-you-go regime is more unequal than the respective income distribution under the fully-funded regime. Furthermore if a stricter condition (36) holds, then 
income distribution in DPE under the PAYG regime is more unequal than the income distribution under the fully-funded regime at all times.

(ii) If the opposite to inequality (41) is satisfied in period $t$, i.e.

$$
p \beta\left(1-p \gamma-\theta_{t}^{F}\right)>p \gamma+(1+p \beta) \delta(1-\delta)^{-1}
$$

is true, then the income distribution in period $t$ under the pay-as-you-go regime is more equal than the respective income distribution under the fully-funded regime. Furthermore if a stricter condition

$$
p \beta\left(1-p \gamma-\theta^{G}\right)>p \gamma+(1+p \beta) \delta(1-\delta)^{-1}
$$

holds (recall that $\theta^{G}$ is defined by formula (38)), then income distribution in DPE under the $P A Y G$ regime is at all times more equal than the income distribution under the FF regime.

It is not hard to see, by substituting expression (38) in inequality (42), that the inequality will be satisfied if $p \gamma$, i.e. the relative size of social security system is sufficiently small. Thus the DPE resulting when a small PAYG system is introduced will be characterized by higher rates of human capital accumulation as well as lower income inequality than the DPE under the corresponding fully funded alternative.

Finally, we note that as in the case of PAYG system (see inequality (39)), increasing longevity has a positive effect on DPE education tax rates under the FF regime. The following fact is proved in the Appendix:

Lemma 5: Assume that Condition 3 is satisfied. Then under fully funded social security the DPE education tax rate is an increasing function of longevity, i.e. $\frac{\partial \theta_{t}^{F}}{\partial p}>0$ holds for all $t$. 
Lemma 5 along with inequality (39) confirm the understanding that public pension systems, both PAYG and fully funded, generate support for public investment in education. Indeed, according to these results this support is the stronger the higher survival to retirement.

\section{Concluding Remarks}

Given the ongoing debate regarding the desirability of transition from pay-as-you-go social security regime to a fully-funded one, we compare dynamic equilibria under these two social security systems in an economy where human capital formation is a contributing factor to economic growth and public education provided by the government. We depart from the way social security systems were evaluated in the literature since we consider this issue in a wider framework: under the circumstances where the productivity of future workers can be endogenously affected. We focus on the comparison, date by date, of the equilibria under the PAYG and FF social security regimes with identical defined contribution rates. However, we do not consider a regime where social security system is absent altogether (see, e.g., Karni and Zilcha (1989) where this has been addressed for the case without endogenous growth), since in most developed economies social security programs are in place. Our study has also abstracted from the determination of 'optimal social security tax rate', due to the complexity of the political process under heterogeneous population (Sheshinski and Weiss (1981) analyzed this issue in a partial equilibrium within an economy with homogeneous population). The emphasis of our study is on the linkage between human capital formation and the social security benefits, since the effects of the alternative programs on the productivity of future workers are essential for determining their overall comparative outcomes. 
As far as we know, this paper presents the first analytical study that considers the comparison of pay-as-you-go and fully funded social security systems from the standpoint of their implications for the investment in future workers' productivity. We show that there is a natural link between the provision of defined contribution social security, investment in human capital and economic growth. Given the current ongoing discussion in the US and Europe regarding the transition from PAYG social security to fully funded system, it is important to include in the relevant arguments the measures taken to increase the productivity of the coming generations.

Since the vast majority of countries feature versions of PAYG social security systems (Netherlands and Chile are among the very few exceptions), the results obtained in our theoretical framework cannot be readily subjected to empirical verification. Most of these countries are facing increasing challenges to sustainability of their social security programs due to demographic changes (increasing longevity combined with falling fertility). Our study suggests that the ongoing discussions regarding transition to a fully funded system should take into account its effect on public education funding which is an important factor in increasing labor productivity, thus plays an important role in neutralizing adverse effects of falling dependency ratios. 


\section{Appendix}

Proof of Proposition 1: Since the two DCE's start from the same initial $K_{0}$ and distribution $h_{0}(\omega)$, we obtain $\left[w_{0} H_{0}\right]^{F}=\left[w_{0} H_{0}\right]^{G}$. Since according to Condition 2 the same education tax rates are applied under both social security regimes, this along with expressions (18) and (27) implies:

$$
K_{1}^{G}<\frac{p \beta\left(1-p \gamma-\theta_{0}\right)\left(w_{0} H_{0}\right)^{G}}{(1+p \beta)}<\frac{p \beta\left(1-\theta_{0}\right)\left(w_{0} H_{0}\right)^{F}}{1+p \beta}=K_{1}^{F}
$$

At the same time we have $X_{0}^{G}=\theta_{0}\left(w_{0} H_{0}\right)^{G}=X_{0}^{F}=\theta_{0}\left(w_{0} H_{0}\right)^{F}$, so (1) and (6) yield $H_{1}^{G}=H_{1}^{F}$. The last equality combined with (A1) and (9) means that $Y_{1}^{G}<Y_{1}^{F}$ and therefore according to (12) we obtain $\left[w_{1} H_{1}\right]^{G}<\left[w_{1} H_{1}\right]^{F}$.

We now apply the induction argument. Indeed, provided that $\left[w_{t} H_{t}\right]^{G}<\left[w_{t} H_{t}\right]^{F}$ we can write similarly to (A1):

$$
K_{t+1}^{G}<\frac{p \beta\left(1-p \gamma-\theta_{t}\right)\left(w_{t} H_{t}\right)^{G}}{(1+p \beta)}<\frac{p \beta\left(1-\theta_{t}\right)\left(w_{t} H_{t}\right)^{F}}{1+p \beta}=K_{t+1}^{F}
$$

Since $X_{t}^{G}=\theta_{t}\left(w_{t} H_{t}\right)^{G}<X_{t}^{F}=\theta_{t}\left(w_{t} H_{t}\right)^{F}$ we conclude from (1) and (6) that $H_{t+1}^{G}<H_{t+1}^{F}$. Then due to (A2) similarly to the above logic $Y_{t+1}^{G}<Y_{t+1}^{F}$ and thereby $\left[w_{t+1} H_{t+1}\right]^{G}<\left[w_{t+1} H_{t+1}\right]^{F}$, which completes the induction proof.

\section{Proof of Lemma 5:}

Differentiating equation (38) with respect to longevity parameter $p$ and rearranging we reach, 
(A3)

$$
\begin{array}{r}
\frac{d \theta}{d p}\left[\frac{1+p \beta}{\left(1-g_{t}(\omega)-\theta\right)^{2}}-\frac{p \beta(1-\delta)}{(1-\theta)^{2}}+\frac{p \beta(1-\delta)(1-\sigma)}{\theta^{2}}\right]= \\
=-\frac{\beta}{1-g_{t}(\omega)-\theta}+\frac{\beta(1-\delta)}{1-\theta}+\frac{\beta(1-\delta)(1-\sigma)}{\theta}
\end{array}
$$

By comparing equation (40) with the right-hand-side of (A3) we can conclude that the latter is positive when $\theta=\theta_{t}^{F}(\omega)$. Furthermore, the expression

$$
\frac{1+p \beta}{\left(1-g_{t}(\omega)-\theta\right)^{2}}-\frac{p \beta(1-\delta)}{(1-\theta)^{2}}+\frac{p \beta(1-\delta)(1-\sigma)}{\theta^{2}}
$$

in the left-hand-side equals to $-\frac{\partial^{2}}{\partial \theta^{2}} V_{t}^{F}\left(\omega, \theta_{t}\right)$ which, as has been noted, is positive when $g_{t}(\omega) \geq 0$ i.e., when $h_{t}(\omega)>H_{t}$. Therefore $\frac{\partial \theta_{t}^{F}(\omega)}{\partial p}>0$ is true whenever $h_{t}(\omega)>H_{t}$. This fact establishes the Lemma's result because according to Condition 3 the inequality $h_{t}(\omega)>H_{t}$ holds for the median voter and thereby $\frac{\partial \theta_{t}^{F}}{\partial p}>0$. 


\section{References}

Atkinson, A. B. (1970). “On the Measurement of Inequality,” Journal of Economic Theory 2, 244-263.

Boldrin, M. and A. Montes (2005). "The Intergenerational State Education and Pensions," Review of Economic Studies 72, 651-664.

Comparative Study of Electoral Systems (2005), www.cses.org. CSES Module 2, advance release. Ann Arbor, Michigan, Center for Political Studies, Institute for Social Research.

Diamond, P. (1999). Issues in Privatizing Social Security, Report of an expert Panel of the National Academy of Social Insurance, MIT Press (Cambridge, MA).

Diamond, P. and P. R. Orszag (2005). "Saving Social Security," Journal of Economic Perspectives 19 (2), 11-32.

Docquier, F. and O. Paddison. (2003). "Growth and Equity Effects of PAYG Pension Plans," Journal of Macroeconomics 25, 47-71.

Feldstein, M. (1974). "Social Security, Induced Retirement, and Aggregate Capital Formation," Journal of Political Economy 23, 905-926.

Feldstein, M. (2005). "Structural Reform of Social Security," Journal of Economic Perspectives $19(2), 33-55$.

Glomm, G. and M. Kaganovich (2003). "Distributional Effects of Public Education in an Economy with Public Pensions," International Economic Review 44, 917-937.

Gradstein, M. and M. Kaganovich (2004), “Aging Population and Education Finance,” Journal of Public Economics 88, 2469-2485.

Hines, J.R. and T. Taylor (2005). "Shortfalls in the Long Run: Predictions about the Social Security Trust Fund," Journal of Economic Perspectives 19(2), 3-9.

Kaganovich, M. and I. Zilcha (1999). "Education, Social Security, and Growth," Journal of Public Economics 71, 289-309.

Karni, E. and I. Zilcha (1989). "Aggregate and Distributional Effects of Fair Social Security," Journal of Public Economics 40, 37-56.

Karni, E. and I. Zilcha (1995)."Technological Progress and Income Inequality: A Model with Human capital and Bequests," Economic Theory 5, 277-294.

Kemnitz, A. (2000). "Social Security, Public Education, and Growth in a Representative Democracy," Journal of Population Economics 13, 443-462. 
Köthenbürger, M. and P. Poutvaara (2006). "Social Security Reform and Investment in Education: Is There Scope for a Pareto Improvement?" Economica 73, 299-319.

Lambrecht, S., P. Michel, and J.-P. Vidal (2005). "Public Pensions and Growth," European Economic Review 49, 1261-1281.

Mahler, V.A. (2006). "Electoral Turnout and Income Redistribution by the State: A CrossNational Analysis of the Developed Democracies." Luxemburg Income Study Working Paper Series. Working Paper No. 455.

Nelson, P. (1999) "Redistribution and the Income of the Median Voter," Public Choice 98, 187 194.

Pecchenino, R.A. and K.R. Utendorf (1999). "Social Security, Social Welfare and the Aging Population," Journal of Population Economics 12, 607-623.

Pogue, T.F. and L.G. Sgontz (1977). "Social Security and Investment in Human Capital," National Tax Journal 30 (2), 157-169.

Poutvaara, P. (2006) "On the Political Economy of Social Security and Public Education," Journal of Population Economics 19, 345-365.

Sheshinski, E. and Y. Weiss (1981). "Uncertainty and Optimal Social Security Systems," Quarterly Journal of Economics 96, 189-206.

Sinn, H.-W. (2000). "Why a Funded Pension is Useful and Why it is not Useful," International Tax and Public Finance 7, 389-410.

Soares, J. (2006) "A Dynamic General Equilibrium Analysis of the Political Economy of Public Education," Journal of Population Economics 19, 367-389.

Yaari, M. (1965). "Uncertain Lifetime, Insurance and the Theory of the Consumer," Review of Economic Studies 32, 137-150.

Zhang, J. and J. Zhang (1998). "Social Security, Intergenerational Transfers, and Endogenous Growth," Canadian Journal of Economics 31, 1225-1241. 


\section{CESifo Working Paper Series}

for full list see www.cesifo-group.org/wp

(address: Poschingerstr. 5, 81679 Munich, Germany, office@cesifo.de)

2289 Mikael Priks, Do Surveillance Cameras Affect Unruly Behavior? A Close Look at Grandstands, April 2008

2290 Marianna Belloc and Daniela Federici, A Two-Country NATREX Model for the Euro/Dollar, April 2008

2291 Nicolas Treich, The Value of a Statistical Life under Ambiguity Aversion, April 2008

2292 J. Atsu Amegashie, Socially-Tolerable Discrimination, April 2008

2293 M. Hashem Pesaran and Andreas Pick, Forecasting Random Walks Under Drift Instability, April 2008

2294 Steven Brakman, Gus Garita, Harry Garretsen and Charles van Marrewijk, Unlocking the Value of Cross-Border Mergers and Acquisitions, May 2008

2295 Eric O’N. Fisher and Kathryn G. Marshall, The Structure of the American Economy, May 2008

2296 Claudia M. Buch and Martin Schlotter, Regional Origins of Employment Volatility: Evidence from German States, May 2008

2297 Helmuth Cremer, Philippe De Donder, Dario Maldonado and Pierre Pestieau, Taxing Sin Goods and Subsidizing Health Care, May 2008

2298 Reinhilde Veugelers and Frederick van der Ploeg, Reforming European Universities: Scope for an Evidence-Based Process, May 2008

2299 Jon H. Fiva and Lars J. Kirkebøen, Does the Housing Market React to New Information on School Quality?, May 2008

2300 Tina Klautke and Alfons J. Weichenrieder, Interest Income Tax Evasion, the EU Savings Directive, and Capital Market Effects, May 2008

2301 Harald Badinger and Peter Egger, GM Estimation of Higher Order Spatial Autoregressive Processes in Panel Data Error Component Models, May 2008

2302 Jan K. Brueckner, Slot-Based Approaches to Airport Congestion Management, May 2008

2303 Sören Blomquist, Vidar Christiansen and Luca Micheletto, Public Provision of Private Goods and Nondistortionary Marginal Tax Rates, May 2008

2304 Dan Anderberg and Alessandro Balestrino, The Political Economy of Post-Compulsory Education Policy with Endogenous Credit Constraints, May 2008 
2305 Tomer Blumkin, Yoram Margalioth and Efraim Sadka, The Role of Stigma in the Design of Welfare Programs, May 2008

2306 Vesa Kanniainen and Paolo M. Panteghini, Tax Neutrality: Illusion or Reality? The Case of Entrepreneurship, May 2008

2307 Thomas Dohmen, Armin Falk, David Huffman and Uwe Sunde, The Intergenerational Transmission of Risk and Trust Attitudes, May 2008

2308 Guglielmo Maria Caporale and Mario Cerrato, Using Chebyshev Polynomials to Approximate Partial Differential Equations, May 2008

2309 Peter Egger and Doina Maria Radulescu, Labour Taxation and Foreign Direct Investment, May 2008

2310 Laurent Linnemer, Dissipative Advertising Signals Quality even without Repeat Purchases, May 2008

2311 Jordi Jofre-Monseny and Albert Solé-Ollé, Which Communities should be afraid of Mobility? The Effects of Agglomeration Economies on the Sensitivity of Firm Location to Local Taxes, May 2008

2312 Andreas Haufler and Ferdinand Mittermaier, Unionisation Triggers Tax Incentives to Attract Foreign Direct Investment, May 2008

2313 Ronel Elul and Piero Gottardi, Bankruptcy: Is it enough to Forgive or must we also Forget?, May 2008

2314 Andreas Irmen and Johanna Kuehnel, Productive Government Expenditure and Economic Growth, May 2008

2315 Beate Henschel, Carsten Pohl and Marcel Thum, Demographic Change and Regional Labour Markets: The Case of Eastern Germany, May 2008

2316 Gabriel Felbermayr, Wido Geis and Wilhelm Kohler, Restrictive Immigration Policy in Germany: Pains and Gains Foregone?, May 2008

2317 Michael Hofmann, Gerhard Kempkes and Helmut Seitz, Demographic Change and Public Sector Budgets in a Federal System, May 2008

2318 Paul De Grauwe, Macroeconomic Modeling when Agents are Imperfectly Informed, June 2008

2319 Johann K. Brunner and Susanne Pech, Optimum Taxation of Inheritances, June 2008

2320 Thomas Eichner and Marco Runkel, Corporate Income Taxation of Multinationals in a General Equilibrium Model, June 2008

2321 Rainald Borck and Matthias Wrede, Subsidies for Intracity and Intercity Commuting, June 2008 
2322 Patricia Apps and Ray Rees, Testing the Pareto Efficiency of Household Resource Allocations, June 2008

2323 Amihai Glazer, Vesa Kanniainen and Panu Poutvaara, Firms' Ethics, Consumer Boycotts, and Signalling, June 2008

2324 Claudia M. Buch, Jörg Döpke and Kerstin Stahn, Great Moderation at the Firm Level? Unconditional vs. Conditional Output Volatility, June 2008

2325 Helmuth Cremer, Philippe De Donder, Dario Maldonado and Pierre Pestieau, Forced Saving, Redistribution and Nonlinear Social Security Schemes, June 2008

2326 M. Hashem Pesaran and Paolo Zaffaroni, Optimal Asset Allocation with Factor Models for Large Portfolios, June 2008

2327 Harald Badinger and Peter Egger, Horizontal versus Vertical Interdependence in Multinational Activity, June 2008

2328 Jan K. Brueckner and Harris Selod, A Theory of Urban Squatting and Land-Tenure Formalization in Developing Countries, June 2008

2329 Paolo M. Panteghini, Corporate Debt, Hybrid Securities and the Effective Tax Rate, June 2008

2330 Guglielmo Maria Caporale, Juncal Cuñado and Luis A. Gil-Alana, Modelling Long-Run Trends and Cycles in Financial Time Series Data, June 2008

2331 Avi Ben-Bassat and Momi Dahan, Social Identity and Voter Turnout, June 2008

2332 Martin R. West and Ludger Wößmann, "Every Catholic Child in a Catholic School”: Historical Resistance to State Schooling, Contemporary Private Competition, and Student Achievement across Countries, June 2008

2333 Erkki Koskela and Panu Poutvaara, Outsourcing and Labor Taxation in Dual Labor Markets, June 2008

2334 Philippe Choné and Laurent Linnemer, Optimal Litigation Strategies with Signaling and Screening, June 2008

2335 Albert Solé-Ollé and Pilar Sorribas-Navarro, Does Partisan Alignment Affect the Electoral Reward of Intergovernmental Transfers?, June 2008

2336 Antonio Cabrales and Piero Gottardi, Markets for Information: Of Inefficient Firewalls and Efficient Monopolies, June 2008

2337 Sumon Majumdar and Sharun W. Mukand, The Leader as Catalyst - on Leadership and the Mechanics of Institutional Change, June 2008

2338 Ulrich Hange, Tax Competition, Elastic Labor Supply, and Growth, June 2008 
2339 Guy Laroque and Bernard Salanié, Does Fertility Respond to Financial Incentives?, June 2008

2340 Adriano Paggiaro, Enrico Rettore and Ugo Trivellato, The Effect of Extending the Duration of Eligibility in an Italian Labour Market Programme for Dismissed Workers, June 2008

2341 Helmut Seitz, Minimum Standards, Fixed Costs and Taxing Autonomy of Subnational Governments, June 2008

2342 Robert S. Chirinko, Leo de Haan and Elmer Sterken, Asset Price Shocks, Real Expenditures, and Financial Structure: A Multi-Country Analysis, July 2008

2343 Wolfgang Leininger, Evolutionarily Stable Preferences in Contests, July 2008

2344 Hartmut Egger and Udo Kreickemeier, Fairness, Trade, and Inequality, July 2008

2345 Ngo Van Long and Bodhisattva Sengupta, Yardstick Competition, Corruption, and Electoral Incentives, July 2008

2346 Florian Baumann, Employment Protection: The Case of Limited Enforceability, July 2008

2347 Alessandro Balestrino, Cinzia Ciardi and Claudio Mammini, On the Causes and Consequences of Divorce, July 2008

2348 Dirk Schindler and Benjamin Weigert, Insuring Educational Risk: Opportunities versus Income, July 2008

2349 Lammertjan Dam and Ben J. Heijdra, The Environmental and Macroeconomic Effects of Socially Responsible Investment, July 2008

2350 Avner Greif, Contract Enforcement and Institutions among the Maghribi Traders: Refuting Edwards and Ogilvie, July 2008

2351 Helmuth Cremer, Philippe De Donder, Dario Maldonado and Pierre Pestieau, Habit Formation and Labor Supply, July 2008

2352 Francesco Menoncin and Paolo M. Panteghini, The Johansson-Samuelson Theorem in General Equilibrium: A Rebuttal, July 2008

2353 Michael Kaganovich and Itzhak Zilcha, Alternative Social Security Systems and Growth, July 2008 